\title{
A retrospective analysis of risk factors in recurrent hemoptysis patients with non-bronchial systematic artery feeding
}

\author{
Jian Zhang, Lili Zheng, Tian Zhao, Shiyong Huang, Wenhao Hu \\ Department of Interventional Radiology, First Affiliated Hospital of Wenzhou Medical University, Wenzhou, China \\ Contributions: (I) Conception and design: J Zhang; (II) Administrative support: W Hu; (III) Provision of study materials or patients: W Hu; (IV) \\ Collection and assembly of data: T Zhao; (V) Data analysis and interpretation: L Zheng; (VI) Manuscript writing: All authors; (VII) Final approval of \\ manuscript: All authors. \\ Correspondence to: Wenhao Hu. Department of Interventional Radiology, First Affiliated Hospital of Wenzhou Medical University, Shangcai Village, \\ Nanbaixiang Street, Ouhai District, Wenzhou, China. Email: 403389279@qq.com.
}

\begin{abstract}
Background: Hemoptysis is a symptom of a life-threatening condition. Bronchial artery embolization (BAE) is recommended to control hemoptysis. However, non-bronchial systematic arteries (NBSAs) can be culprit vessels, particularly in recurrent hemoptysis patients after embolization, according to recent studies. Therefore, the purpose of the present study was to retrospectively assess the risk factors of recurrent hemoptysis patients with NBSA feeding after interventional embolization.

Methods: Between January 2014 and December 2017, a total of 545 patients underwent interventional embolization for hemoptysis. A total of 93 patients who were confirmed to have NBSA feeding and underwent embolization were enrolled. Patients' demographic characteristics, clinical information, laboratory tests, imaging findings, and embolization outcomes were reviewed. The Kaplan-Meier method and logistic regression analysis were performed for recurrence-free survival rates and risk factors associated with rebleeding, respectively.

Results: Clinical success was achieved in 40.9\% (9/22) of patients who underwent embolization prior to computed tomography (CT) bronchial arteriography (BA), and in 98.6\% (70/71) of patients who underwent CTBA first. The median follow-up duration was 511 days (range, 1-1,539 days). CTBA performed after the first embolization $(\mathrm{P}<0.001)$ and elevated pre-embolization $\mathrm{C}$-reactive protein $(\mathrm{P}<0.05)$ were associated with hemoptysis recurrence in multivariate regression analyses.

Conclusions: Multidetector CTBA was recommended prior to embolization, as it shows the diagnostic value for detecting NBSA. Elevated pre-embolization C-reactive protein was found to be associated with rebleeding after embolization.
\end{abstract}

Keywords: Multidetector computed tomography (MDCT); non-bronchial systematic artery (NBSA); embolization; hemoptysis recurrence; C-reactive protein

Submitted May 09, 2020. Accepted for publication Oct 26, 2020.

doi: 10.21037/atm-20-5544

View this article at: http://dx.doi.org/10.21037/atm-20-5544

\section{Introduction}

Patients with acute hemoptysis account for the majority of emergency department presentations due to its possibility of asphyxiation. Bronchoscopy is helpful for respiratory doctors to identify the site of bleeding and controlling symptoms when using a rigid endoscope (1).
However, computed tomography (CT) is equally capable of localizing bleeding and is more effective in detecting underlying diseases, such as tumors and bronchiectasis (2). Additionally, CT bronchial arteriography (BA), in particular multidetector CT (MDCT) BA can identify uncommon etiologies that are not easily detected on non-contrast 
CT. It has been recommended as an essential modality in assisting with the planning of bronchial artery embolization (BAE), as CTBA can reveal normally located arteries and ectopic bronchial arteries, such as non-bronchial systematic arteries (NBSAs) that are bleeding culprit vessels (3-8), which were most common in chronic lung disease, with bronchiectasis accounting most, followed by tuberculosis and pulmonary aspergillosis.

BAE has been demonstrated to be an effective and safe approach for hemoptysis (9). However, recurrence during long-term follow up is common, with recurrence rates as high as $45 \%$ (9-12). Bronchial arteries are responsible for most hemoptysis cases that need embolization or surgical resection, but bleeding owing to NBSA is not rare, which were embolized in the first session in approximately $40-62 \%$ patients $(8,9)$. Failure to identify culprit vessels at initial angiography may increase the possibility of recurrent hemoptysis after BAE $(13,14)$, especially in transcatheter embolization without CTBA examination, the clinical success rate of embolization of NBSA in the treatment of hemoptysis was reported as about $60 \%$. However, research on the risk factors related to hemoptysis recurrence after BAE for these patients has been underreported in the literature. Therefore, the aim of the present study was to retrospectively investigate the risk factors of recurrent hemoptysis patients with NBSA feeding after interventional embolization.

We present the following article in according with the STROBE reporting checklist (available at http://dx.doi. org/10.21037/atm-20-5544).

\section{Methods}

\section{Study design}

From January 2014 to December 2017, a total of 545 hemoptysis patients underwent interventional embolization in our department. Of these, 93 patients who were confirmed as having NBSA by 320-row MDCT and digital subtraction angiography (DSA) were enrolled in the present study. CTBA was performed prior interventional embolization in 71 patients and after embolization in 22 patients. The enrollment details are summarized in Figure 1.

The study was conducted in accordance with the Declaration of Helsinki (as revised in 2013). The ethical approval was not required in our hospital, because this is a retrospective study, not prospective studies, and the requirement for informed consent was waived.

\section{CT technique}

CTBA images were achieved with a 320-row, 640-slice multidetector scanner (Aquilion ONEVISION; Toshiba Medical Systems). The scan of the upper part of the subclavian artery to the bilateral renal artery was accepted as the field of view. The scanning parameters were based on the manufacturer's recommendations.

\section{CT imaging analysis}

All images were analyzed by two independent radiologists with more than 10 years of experience. If consensus could not be reached, a third radiologist reconciled the contradictions. The characteristics of the culprit vessels in the CTBA included thickening (vessel diameter $>2 \mathrm{~mm}$ ) and enlargement or distortion of the BA or NBSA supplying the lesions. In addition to the above CT manifestations, NBSA features included not accompanying the bronchus, not passing through the hilar, passing through the subpulmonary ligaments or adjacent pleura into the pulmonary parenchyma, and pleural thickening. The CTBA focused on the number, location, and source of culprit vessels.

\section{Interventional embolization procedure}

All patients signed an informed consent form before the DSA procedure. The femoral artery or radial artery was punctured by Seldinger technique. All relevant systematic arteries (e.g., intercostal artery, subclavian artery, internal thoracic artery) underwent selective arteriography with 5-F curved catheters (Cobra; Cordis) or a left gastric artery catheter (Cook). A microcatheter (2.9-Fr swan-neck microcatheter; Merit Maestro; or 2.7-Fr Progreat; Terumo) was used for superselection of BA or NBSA, noting the spinal arteries' origin from the $\mathrm{BA}$ or intercostal arteries.

The arteries were embolized if any of the following findings were viewed on DSA: (I) contrast agent overflow; (II) parenchymal staining; (III) thickening and tortuous artery; (IV) disorder and roughness of terminal artery; and (V) bronchial-pulmonary artery shunts. Interventional embolization were performed with Embosphere particles (300-500, 500-700, or 700-900 $\mu \mathrm{m}$ in diameter; Biosphere Medical) with or without gelatin sponge granules or strips. Coils or medical glue were used if obvious bronchialpulmonary artery shunts were present. The injection of embolization materials was terminated when the contrast medium did not clear within three cardiac cycles. 


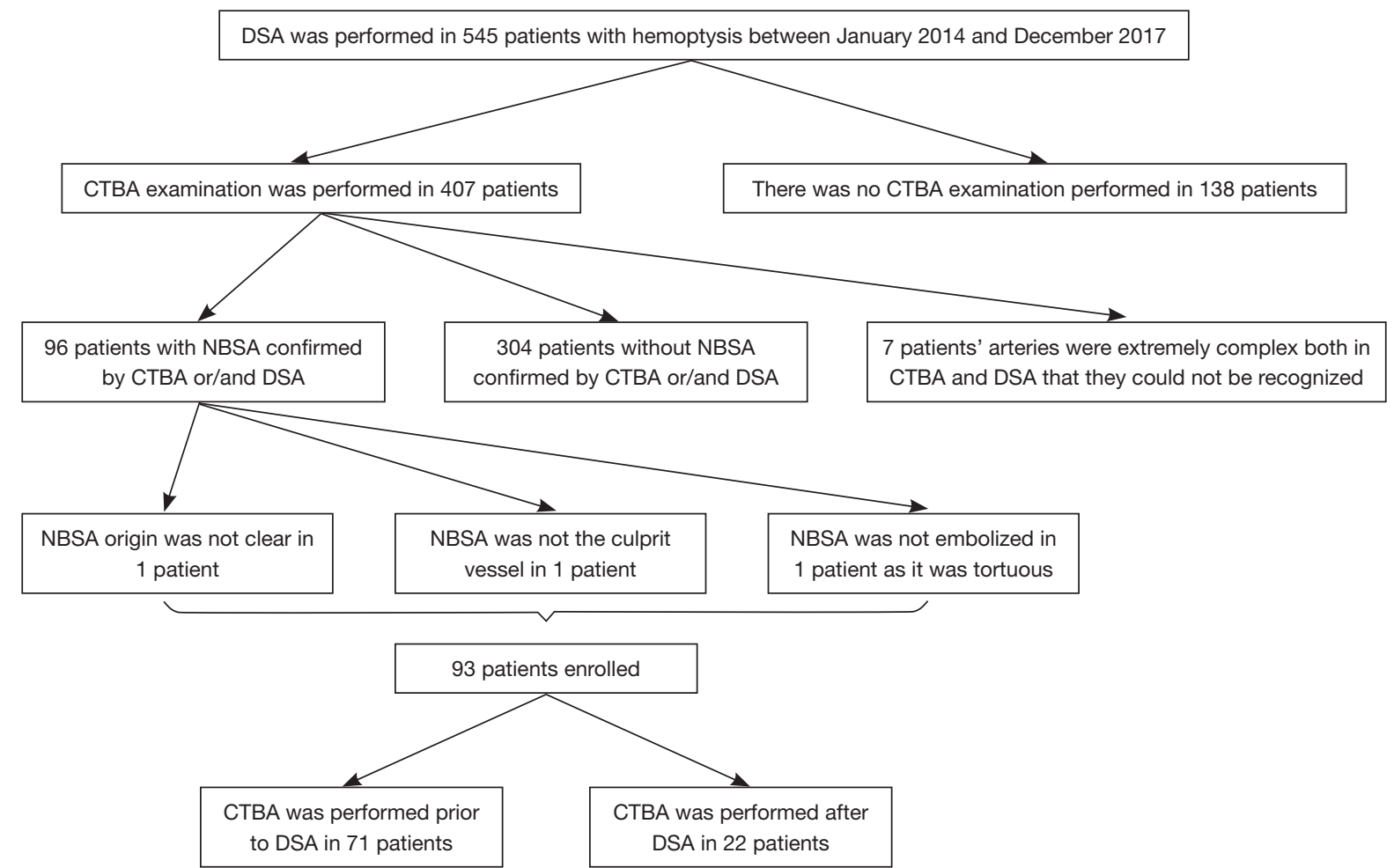

Figure 1 The enrollment details. CTBA, computed tomography bronchial arteriography; DSA, digital subtraction angiography; NBSA, non-bronchial systematic arteries.

\section{Assessment and follow up}

The amount of bleeding was defined as severe hemoptysis ( $\geq 300 \mathrm{~mL} /$ day), moderate hemoptysis (100-300 mL/day), and mild hemoptysis $(\leq 100 \mathrm{~mL} /$ day).

The patients was observed for 1 week after the embolization procedure and discharged if there was no hemoptysis recurrence. Repeated embolization or CTBA examination should be performed if recurrent hemoptysis was present within 1 month to determine if there are any missing or recanalization culprit arteries (15).

Clinical success was defined as no hemoptysis within 24 hours after BAE $(16,17)$. Survival and hemoptysis recurrence were retrospectively analyzed after following up the patients by telephone or interviewing the doctors in charge. Follow up was set from the date of first embolization to the terminal point. The recurrence-free time was defined as the time from the first embolization procedure to the second embolization procedure or to the patients' death or last follow-up.

\section{Statistical analysis}

Data analysis was performed with SPSS version 17.0 software. The recurrence-free survival likelihood was calculated by the Kaplan-Meier method and log-rank test. Logistic multivariate analysis was used to reveal independent risk factors associated with hemoptysis recurrence. Hazard ratios (HR) with $95 \%$ confidence intervals $(\mathrm{CI})$ were calculated. $\mathrm{P}<0.05$ was considered statistically significant.

\section{Results}

\section{Patient demographics}

The demographics of the 93 patients are summarized in Table 1 (61 males and 32 females, median age: 59 years, range, 15-80 years). The most common comorbidity was hypertension $(n=27)$, followed by diabetes mellitus $(n=14)$. All patients underwent CTBA. 
Table 1 Clinical characteristics of hemoptysis patients

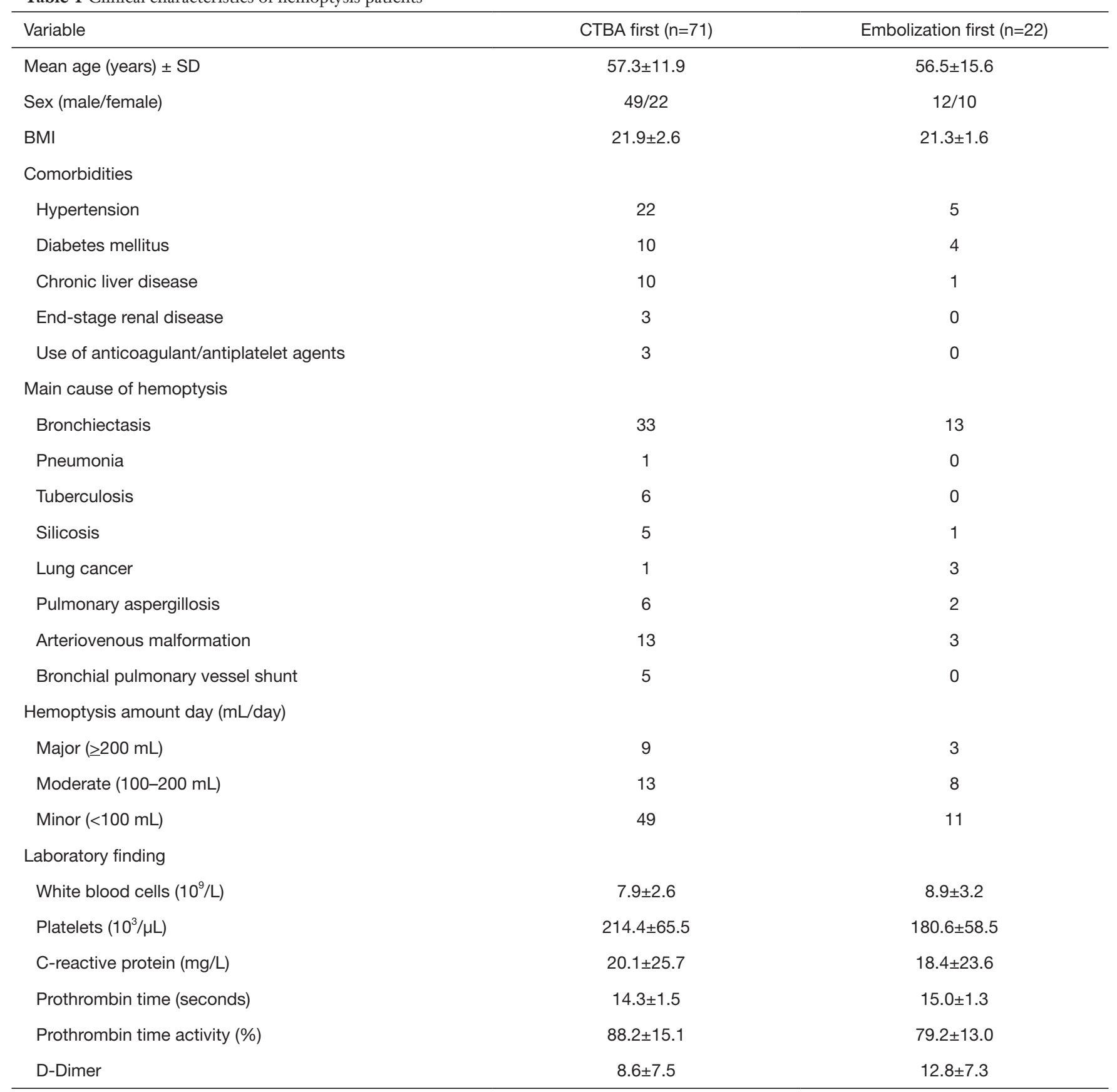

BMI, body mass index; CTBA, computed tomography bronchial arteriography; SD, standard deviation.

\section{CTBA findings}

A total of 151 NBSA and 240 BA were identified in 93 patients. Two patients had single NBSA without bronchial arteries. After retrospectively analyzing the CT findings, the most frequently involved foci was the right lung. The common origins of NBSA were the internal mammary arteries $(\mathrm{n}=58,38.4 \%)$, followed by the intercostal arteries $(\mathrm{n}=42,27.8 \%)$ and subclavian arteries $(\mathrm{n}=37,24.5 \%)$. The CTBA findings of these arteries are summarized in Table 2. 
Table 2 CTBA and DSA findings of bronchial and non-bronchial systematic arteries

\begin{tabular}{|c|c|c|}
\hline CTBA and DSA findings & CTBA first $(n=71)$ & Embolization first $(n=22)$ \\
\hline Right & 101 & 25 \\
\hline Left & 86 & 28 \\
\hline Bronchial pulmonary vessel shunt $(n=71)$ & 53 & 18 \\
\hline \multicolumn{3}{|l|}{ Location } \\
\hline Right & 69 & 11 \\
\hline Left & 37 & 34 \\
\hline \multicolumn{3}{|l|}{ Origin } \\
\hline Subclavian artery & 29 & 8 \\
\hline Lateral thoracic artery & 0 & 5 \\
\hline Esophageal common artery & 2 & 0 \\
\hline Thyrocervical trunk & 2 & 0 \\
\hline Inferior phrenic artery & 2 & 0 \\
\hline Cephalic artery & 1 & 0 \\
\hline Brachiocephalic trunk & 0 & 1 \\
\hline Left circumflex branch & 0 & 1 \\
\hline
\end{tabular}

CTBA, computed tomography bronchial arteriography; DSA, digital subtraction angiography.

\section{BAE outcomes}

Clinical success was achieved in 40.9\% (9/22) of patients who underwent embolization prior to CTBA, and $98.6 \%$ (70/71) in patients who underwent CTBA first. The median follow-up duration was 511 days (range, 1-1,539 days). There were no major complications or embolization-related deaths. The estimated hemoptysis-free survival rates in the two groups at 1,2 , and 3 years were $80.3 \%$ versus $31.8 \%$, $40.8 \%$ versus $18.2 \%, 11.3 \%$ versus $0 \%$, respectively.

The Kaplan-Meier survival curves and log-rank tests were performed to evaluate the risk factors that influenced the recurrence-free period. There were four factors associated with short recurrence-free time after embolization: embolization first $(\mathrm{P}<0.001)$, elevated preembolization $\mathrm{C}$-reactive protein $(\mathrm{P}=0.001)$, prothrombin time above the normal range $(\mathrm{P}=0.029)$, and decreased prothrombin time activity $(\mathrm{P}=0.010)$ (Figures $2-5)$. Multivariate regression analysis identified embolization first (HR: $32.778,95 \%$ CI: 7.049-152.411, $\mathrm{P}<0.001$ ) and elevated pre-embolization C-reactive protein (HR: 3.618, 95\% CI: $1.050-12.470, \mathrm{P}=0.042$ ) as independent risk factors for hemoptysis recurrence after embolization (Table 3).

\section{Discussion}

The present study showed the necessity for hemoptysis patients to undergo CTBA and to correct coagulation abnormalities before embolization to prevent hemoptysis recurring after a short period of time. Moreover, an elevated C-reactive protein level prior to first embolization was found to significantly affect rebleeding.

BAE is recommended for hemoptysis patients, with a recurrence-free procedure success rate of approximately $90 \%$ (18). Previous studies have reported the recurrent hemoptysis rate to be approximately $10-30 \%$ (18). In the present study, the incidence of rebleeding was $31.2 \%$ 


\section{Page 6 of 9}

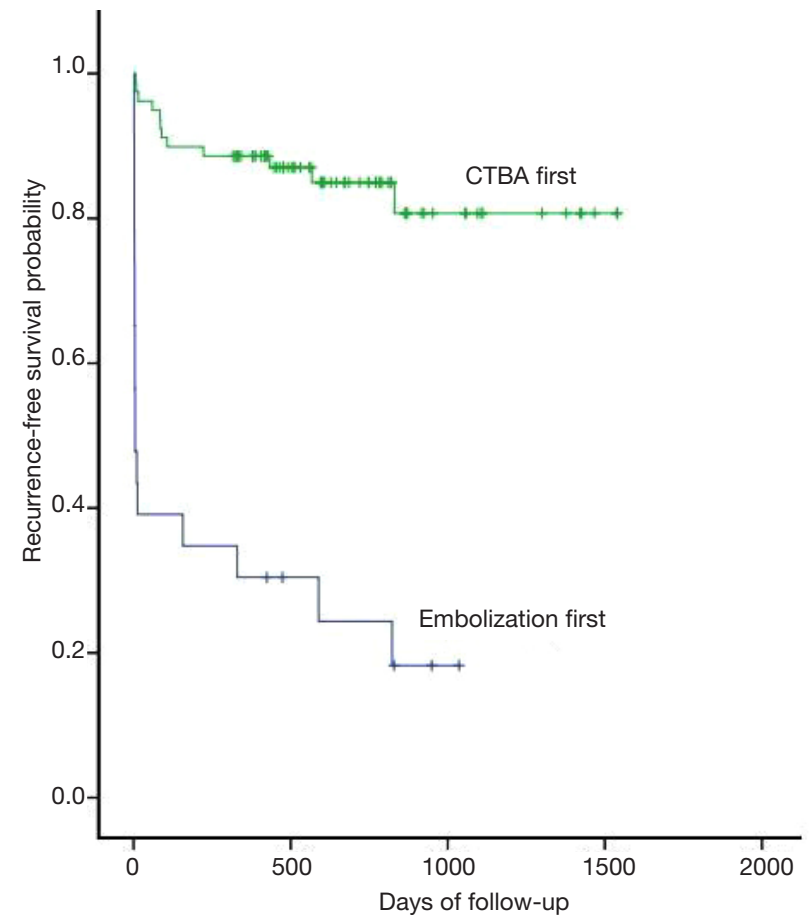

Figure 2 Recurrence-free survival curves of patients who underwent CTBA first or embolization first. $\mathrm{P}<0.001$. CTBA, computed tomography bronchial arteriography.

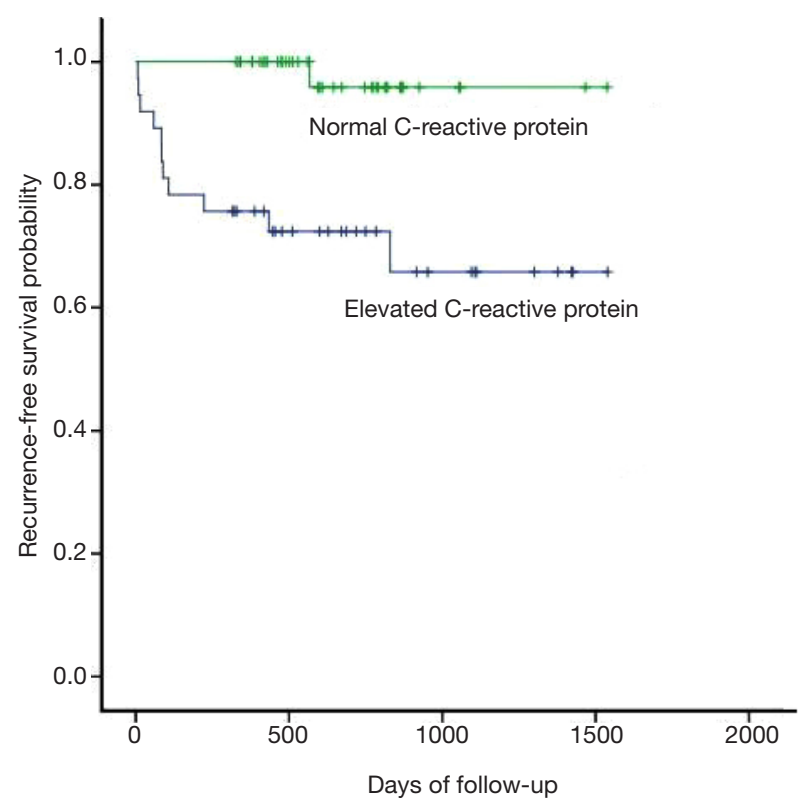

Figure 3 Recurrence-free survival curves of patients who had normal or elevated C-reactive protein. $\mathrm{P}=0.001$.

\section{Zhang et al. Risk factors associated with recurrent hemoptysis}

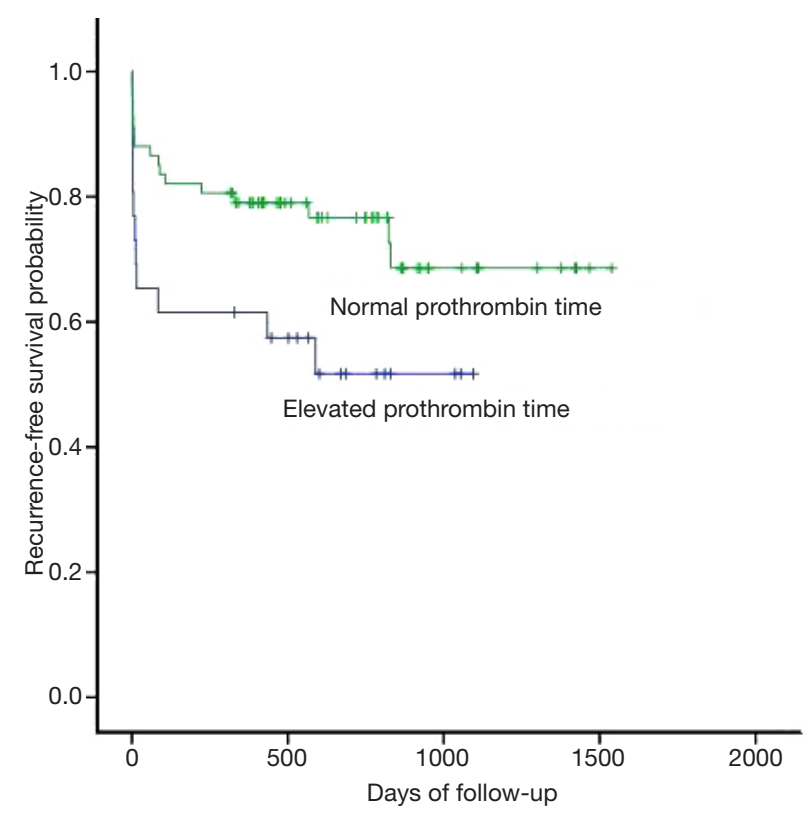

Figure 4 Recurrence-free survival curves of patients who had normal or elevated prothrombin time. $\mathrm{P}=0.029$.

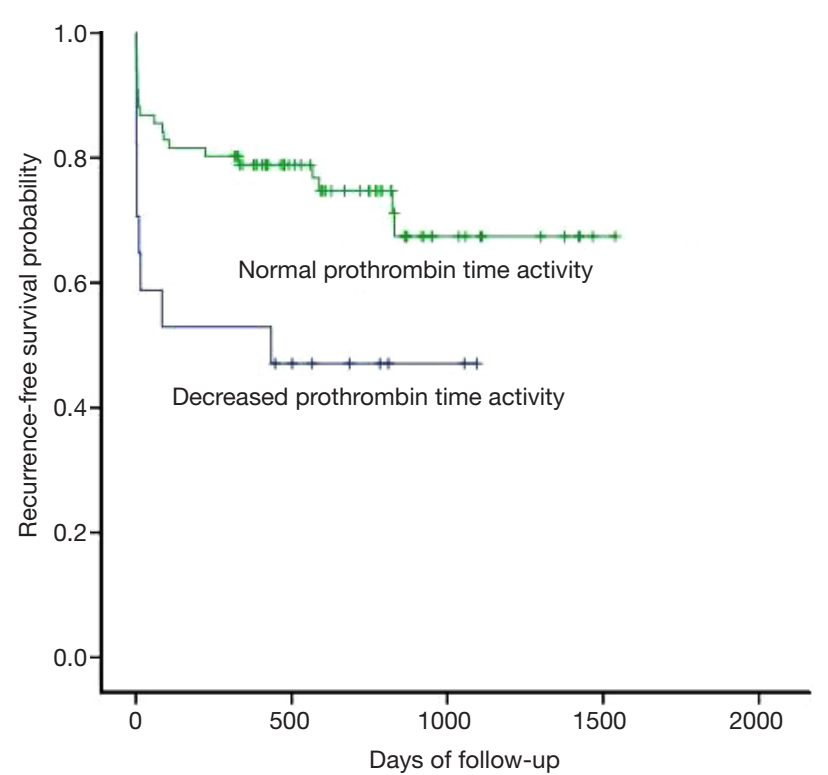

Figure 5 Recurrence-free survival curves of patients who had normal or decreased prothrombin time activity. $\mathrm{P}=0.010$. 
Table 3 Multivariate regression analysis of risk factors associated with recurrent hemoptysis after embolization in the computed tomography bronchial arteriography-first group

\begin{tabular}{lcc}
\hline Variables & Hazard ratio $(95 \% \mathrm{Cl})$ & $\mathrm{P}$ value \\
\hline Embolization first & $32.778(7.049-152.411)$ & 0.000 \\
Elevated pre-embolization C-reactive protein & $3.618(1.050-12.470)$ & 0.042 \\
Elevated prothrombin time & $0.289(0.038-2.272)$ & 0.238 \\
Decreased prothrombin time activity & $8.118(0.818-80.537)$ & 0.074 \\
\hline
\end{tabular}

$\mathrm{Cl}$, confidence interval.

$(\mathrm{n}=29)$, which is higher than that of previous studies (18-20). The higher incidence may be associated with etiology, from immediately controlled, such as bronchiectasis, to easily recurrent, such as pulmonary tuberculosis and aspergillosis $(19,20)$. The common origins of NBSA were the internal mammary arteries $(\mathrm{n}=58,38.4 \%)$, followed by the intercostal arteries $(\mathrm{n}=42,27.8 \%)$ and subclavian arteries $(\mathrm{n}=37,24.5 \%)$, which is similar to previous literature $(5,9,21,22)$. Those NBSA can be easily missed by inexperienced radiologists when performing selective angiography, which may be another reason for the lower incidence of NBSA as culprit vessels reported in previous studies (18-20).

At present, the introduction of NBSA is mainly based on the DSA, which is considered a rare culprit vessel in hemoptysis patients; therefore, missing NBSA in embolization treatment is common and may cause hemoptysis recurrence in a short period of time (5,23-25). With improvements in MDCT technology, CTBA is more frequently used in hemoptysis patients. It has an important role in detecting NBSA as culprit vessels prior to embolization; in the present study, it demonstrated a short rebleeding time after embolization. DSA is less sensitive to NBSA and ectopic BA, and depends on the interventional radiologists' experience. Therefore, CTBA performed before embolization/DSA can detect more culprit vessels and guide interventional radiologists to embolism, and then decrease the possibility of hemoptysis recurrence, especially 320-row MDCT compared with 64-row and 256-row MDCT, according to previous studies (26-36).

Among the laboratory data retrospectively analyzed, elevated C-reactive protein above the normal upper limit prior to the first embolization revealed active inflammation, and was approved as a significant risk factor for rebleeding after treatment. Clinically, a higher C-reactive protein level indicates more severe inflammation (37). CRP level is apparently always greater than it is in case of viral or aseptic meningitis. This distinction is not true with infection elsewhere, for instance, in the respiratory tract. The CRP level reflects activity of the disease and in severe cases, high levels are always seen. The suppressive effect of some preparations of CRP on platelet aggregation, activation, and release reactions is now known to have been due to a coisolating low-molecular-weight material which contaminated these preparations (37). Therefore, hemoptysis patients with lung inflammation are at high risk of hemoptysis recurrence after initial treatment. Unfortunately, we did not analyze the C-reactive protein level at follow up after embolization, thus statistical significance as a risk factor could not be determined, which is a limitation of the present study.

The present study was also limited by its retrospective nature and small sample size. Successful identification and embolization of the bleeding arteries depend on the experience of the interventional radiologists, which may bias the results.

In conclusion, the results revealed that MDCT is a valuable method for identifying NBSA that are easily missed on conventional DSA. We recommend the routine use of high-quality CTBA and the correction of coagulation abnormalities before embolization. Hemoptysis patients with an elevated C-reactive protein level, who are prone to recurrence in a short period of time, should be closely monitored.

\section{Acknowledgments}

The authors thank Dr. Weizhong Zhou (Department of Interventional Radiology, First Affiliated Hospital of Wenzhou Medical University), Dr. Houzhang Sun (Department of Radiology, First Affiliated Hospital of Wenzhou Medical University), and Dr. Yunjun Yang (Department of Radiology, First Affiliated Hospital of Wenzhou Medical University) for their invaluable 
assistance.

Funding: None.

\section{Footnote}

Reporting Checklist: The authors have completed the STROBE reporting checklist. Available at http://dx.doi. org/10.21037/atm-20-5544

Data Sharing Statement: Available at http://dx.doi. org/10.21037/atm-20-5544

Conflicts of Interest: All authors have completed the ICMJE uniform disclosure form (available at http://dx.doi. org/10.21037/atm-20-5544). The authors have no conflicts of interest to declare.

Ethical Statement: The authors are accountable for all aspects of the work in ensuring that questions related to the accuracy or integrity of any part of the work are appropriately investigated and resolved. The study was conducted in accordance with the Declaration of Helsinki (as revised in 2013). The ethical approval was not required in our hospital, because this is a retrospective study, not prospective studies, and the requirement for informed consent was waived.

Open Access Statement: This is an Open Access article distributed in accordance with the Creative Commons Attribution-NonCommercial-NoDerivs 4.0 International License (CC BY-NC-ND 4.0), which permits the noncommercial replication and distribution of the article with the strict proviso that no changes or edits are made and the original work is properly cited (including links to both the formal publication through the relevant DOI and the license). See: https://creativecommons.org/licenses/by-nc-nd/4.0/.

\section{References}

1. Hsiao EI, Kirsch CM, Kagawa FT, et al. Utility of fiberoptic bronchoscopy before bronchial artery embolization for massive hemoptysis. AJR Am J Roentgenol 2001;177:861-7.

2. Bruzzi JF, Remy-Jardin M, Delhaye D, et al. Multidetector row CT of hemoptysis. Radiographics 2006;26:3-22.

3. Hartmann IJ, Remy-Jardin M, Menchini L, et al. Ectopic origin of bronchial arteries: assessment with multidetector helical CT angiography. Eur Radiol 2007;17:1943-53.

4. Gupta M, Srivastava DN, Seith A, et al. Clinical impact of multidetector row computed tomography before bronchial artery embolization in patients with hemoptysis: a prospective study. Can Assoc Radiol J 2013;64:61-73.

5. Yoon W, Kim JK, Kim YH, et al. Bronchial and nonbronchial systemic artery embolization for lifethreatening hemoptysis: a comprehensive review. Radiographics 2002;22:1395-409.

6. Khalil A, Parrot A, Nedelcu C, et al. Severe hemoptysis of pulmonary arterial origin: signs and role of multidetector row CT angiography. Chest 2008;133:212-9.

7. Yoon YC, Lee KS, Jeong YJ, et al. Hemoptysis: bronchial and nonbronchial systemic arteries at 16-detector row CT. Radiology 2005;234:292-8.

8. Remy-Jardin M, Bouaziz N, Dumont P, et al. Bronchial and nonbronchial systemic arteries at multi-detector row CT angiography: comparison with conventional angiography. Radiology 2004;233:741-9.

9. Chun JY, Belli AM. Immediate and long-term outcomes of bronchial and non-bronchial systemic artery embolisation for the management of haemoptysis. Eur Radiol 2010;20:558-65.

10. Menchini L, Remy-Jardin M, Faivre JB, et al. Cryptogenic haemoptysis in smokers: angiography and results of embolisation in 35 patients. Eur Respir J 2009;34:1031-9.

11. Herth F, Ernst A, Becker HD. Long-term outcome and lung cancer incidence in patients with hemoptysis of unknown origin. Chest 2001;120:1592-4.

12. Flume PA, Mogayzel PJ Jr, Robinson KA, et al. Cystic fibrosis pulmonary guidelines: pulmonary complications: hemoptysis and pneumothorax. Am J Respir Crit Care Med 2010;182:298-306.

13. Yoo DH, Yoon CJ, Kang SG, et al. Bronchial and nonbronchial systemic artery embolization in patients with major hemoptysis: safety and efficacy of N-butyl cyanoacrylate. AJR Am J Roentgenol 2011;196:W199-204.

14. Yoon W, Kim YH, Kim JK, et al. Massive hemoptysis: prediction of nonbronchial systemic arterial supply with chest CT. Radiology 2003;227:232-8.

15. Barben J, Robertson D, Olinsky A, et al. Bronchial artery embolization for hemoptysis in young patients with cystic fibrosis. Radiology 2002;224:124-30.

16. Dave BR, Sharma A, Kalva SP, et al. Nine-year singlecenter experience with transcatheter arterial embolization for hemoptysis: medium-term outcomes. Vasc Endovascular Surg 2011;45:258-68.

17. Thompson AB, Teschler H, Rennard SI. Pathogenesis, 
evaluation, and therapy for massive hemoptysis. Clin Chest Med 1992;13:69-82.

18. Gupta A, Sands M, Chauhan NR. Massive hemoptysis in pulmonary infections: bronchial artery embolization. J Thorac Dis 2018;10:S3458-64.

19. Hwang HG, Lee HS, Choi JS, et al. Risk factors influencing rebleeding after bronchial artery embolization on the management of hemoptysis associated with pulmonary tuberculosis. Tuberc Respir Dis (Seoul) 2013;74:111-9.

20. Pathak V, Stavas JM, Ford HJ, et al. Long-term outcomes of the bronchial artery embolization are diagnosis dependent. Lung India 2016;33:3-8.

21. Yamakawa H, Shimizu K, Michimoto K, et al. Transcatheter embolization for hemoptysis associated with anomalous systemic artery in a patient with scimitar syndrome. SpringerPlus 2015;4:422.

22. Keller FS, Rosch J, Loflin TG, et al. Nonbronchial systemic collateral arteries: significance in percutaneous embolotherapy for hemoptysis. Radiology 1987;164:687-92.

23. Kim YG, Yoon HK, Ko GY, et al. Long-term effect of bronchial artery embolization in Korean patients with haemoptysis. Respirology 2006;11:776-81.

24. Chun HJ, Byun JY, Yoo SS, et al. Added benefit of thoracic aortography after transarterial embolization in patients with hemoptysis. AJR Am J Roentgenol 2003;180:1577-81.

25. Jiang S, Sun XW, Yu D, et al. Endovascular embolization of bronchial artery originating from the upper portion of aortic arch in patients with massive hemoptysis. Cardiovasc Intervent Radiol 2014;37:94-100.

26. Zhao T, Wang S, Zheng L, et al. The Value of 320Row Multidetector CT Bronchial Arteriography in Recurrent Hemoptysis after Failed Transcatheter Arterial Embolization. J Vasc Interv Radiol 2017;28:533-541.e1.

27. Furuse M, Saito K, Kunieda E, et al. Bronchial arteries: CT demonstration with arteriographic correlation. Radiology 1987;162:393-8.

28. Morita Y, Takase K, Ichikawa H, et al. Bronchial artery anatomy: preoperative 3D simulation with multidetector CT. Radiology 2010;255:934-43.

Cite this article as: Zhang J, Zheng L, Zhao T, Huang S, $\mathrm{Hu} W$. A retrospective analysis of risk factors in recurrent hemoptysis patients with non-bronchial systematic artery feeding. Ann Transl Med 2020;8(23):1593. doi: 10.21037/atm20-5544
29. Chen MY, Shanbhag SM, Arai AE. Submillisievert median radiation dose for coronary angiography with a second-generation 320-detector row CT scanner in 107 consecutive patients. Radiology 2013;267:76-85.

30. Mahabadi AA, Achenbach S, Burgstahler C, et al. Safety, efficacy, and indications of beta-adrenergic receptor blockade to reduce heart rate prior to coronary CT angiography. Radiology 2010;257:614-23.

31. Lin Y, Chen Z, Yang X, et al. Bronchial and non-bronchial systemic arteries: value of multidetector CT angiography in diagnosis and angiographic embolisation feasibility analysis. J Med Imaging Radiat Oncol 2013;57:644-51.

32. Khan A, Khosa F, Nasir K, et al. Comparison of radiation dose and image quality: 320-MDCT versus 64MDCT coronary angiography. AJR Am J Roentgenol 2011;197:163-8.

33. Kroft LJ, Roelofs JJ, Geleijns J. Scan time and patient dose for thoracic imaging in neonates and small children using axial volumetric 320-detector row CT compared to helical 64-, 32-, and 16- detector row CT acquisitions. Pediatr Radiol 2010;40:294-300.

34. Ponnuswamy I, Sankaravadivelu ST, Maduraimuthu P, et al. 64-detector row CT evaluation of bronchial and nonbronchial systemic arteries in life-threatening haemoptysis. Br J Radiol 2012;85:e666-72.

35. Battal B, Akgun V, Karaman B, et al. Normal anatomical features and variations of bronchial arteries: an analysis with 64-detector-row computed tomographic angiography. J Comput Assist Tomogr 2011;35:253-9.

36. Woo S, Yoon CJ, Chung JW, et al. Bronchial artery embolization to control hemoptysis: comparison of N-butyl-2-cyanoacrylate and polyvinyl alcohol particles. Radiology 2013;269:594-602.

37. Pepys MB, Baltz ML. Acute phase proteins with special reference to $\mathrm{C}$-reactive protein and related proteins (pentaxins) and serum amyloid A protein. Adv Immunol 1983;34:141-212.

(English Language Editor: R. Scott) 